\title{
Transitions and Arrivals
}

\author{
MATTHEW P. ROMANIELLO
}

W ith the arrival of volume 17, our readers will notice there have been some changes to the editorial organization of Sibirica. My predecessor, John Ziker, has stepped away from his role as editor after several years of dedicated service. We are fortunate that he will still be involved with the journal moving forward, taking on the new role of book review editor as well as acting as an associate editor to help with the transition. Dmitry Arzyutov has also joined the journal as a new associate editor. Dmitry produced a special issue for Sibirica last year, "Beyond the Anthropological Texts: History and Theory of Fieldworking in the North," and we look forward to his future contributions to the journal as an exciting new voice in the field. There have also been several changes to the editorial advisory board, beginning with the appointment of Alexander King, who joins it after many years of service as one of our editors. Our other new board members are Alfrid Bustanov, Jessica Graybill, Igor Krupnik, Erika Monahan, and Hiroki Takakura. This established and prominent group only adds to the stature of our returning board members, extending our breadth and depth in the fields, as well as bringing in expertise in new approaches and methodologies that will complement our existing work.

I am the new editor for the journal, working closely with my editorial colleagues. My academic interests have always been focused on the Russian Empire but more recently have transitioned to Siberia. My first book, The Elusive Empire: Kazan and the Creation of Russia, 1552-1671 (2012), focused on Muscovite Russia's early process of managing a multiethnic and multiconfessional polity, and my new book projects have turned toward Russia's global reach into the Middle East, Central Asia, Siberia, and the north Pacific as markets for development, and toward a study of eighteenth-century scientific and medical experts and their role in the formation of a typology of imperial bodies, and the consequences of that hierarchy on Siberia and its indigenous populations. While the turn toward Siberia is a more recent development of my own studies, much of my career to date has been in an editorial capacity. This includes three years as the editor of the Journal of World History, as 
well as the production of three edited volumes-including Tobacco in Russian History and Culture (2010) and Russian History through the Senses (2016), both of which were edited with my colleague Tricia Starks-with another two forthcoming. While my previous journal work has been in history, my edited volumes have been interdisciplinary publications more in line with the ongoing purpose of Sibirica, bringing scholars from diverse fields into conversation over a common purpose. These projects have been made possible with strong support by colleagues across the academic spectrum, and I am pleased that Sibirica's editorial collective is well situated to continue this mission.

Our new volume begins with an open issue following our strong tradition in publishing the best new scholarship in the field of Siberian studies in both anthropology and history. Paul Dukes's article looks at the career of Vilhjalmur Stefansson, a turn-of-the-century explorer and anthropologist, whose work on Wrangel Island and the Arctic Sea became encumbered by changing political events, including the Russian Revolution. Writing in the West, Stefansson challenged the new Soviet Union's claim toward the tsarist empire's former possession and moved the North into the geopolitical center in the early twentieth century. Albina Girfanova's article on Vladimir Arsenyev discusses his fieldwork in the Ussuri taiga and the unique contribution his work makes beyond his well-known novel. Both of these articles challenge the reader to reevaluate established publications with a more detailed and thoughtful reading of the sources, providing essential context for understanding Siberia and the Far North. In addition to these articles analyzing historical figures, this issue presents two essays presenting the results of ongoing fieldwork in Siberia. Svetlana Huusko studies contemporary education practices among Evenki children to understand the ways in which the ideas of "tradition" and "modernity" affect their understanding of their customs and lifestyles in the post-Soviet world. Tatiana Vagramenko discusses the ongoing evangelization efforts among the Nenets in order to explain the growing influence of fundamentalist Baptists in northwestern Russia.

We look forward to bringing forth a mixture of essays looking at both the past and present as we move forward, as well as special issues highlighting important topics for both the specialists in our field and the populations of Siberia. Working alongside my fellow editors and with the advisory board, I am confident we will continue the strong tradition established by my predecessors and continue to make Sibirica an essential home for the best research in our field. I look forward to a successful 2018 and beyond! 